\title{
The safety and efficacy of transcranial direct current stimulation as add-on therapy to fluoxetine in obsessive- compulsive disorder: a randomized, double-blind, sham-controlled, clinical trial
}

Sadegh Yoosefee ${ }^{1,2}$, Man Amanat ${ }^{3}$, Mona Salehi ${ }^{3}$, Seyed Vahid Mousavi ${ }^{4}$, Jamshid Behzadmanesh ${ }^{5}$, Victoria Safary ${ }^{5}$, Ali Yoonesi ${ }^{6}$ and Bahman Salehi ${ }^{5^{*}}$

\begin{abstract}
Background: Obsessive-compulsive disorder (OCD) is an anxiety disorder that causes impairment in daily activities. This study aimed to assess the safety and efficacy of transcranial direct current stimulation (tDCS) as adjunctive therapy with fluoxetine in individuals diagnosed with moderate to severe OCD.

Methods: This is a randomized, double-blind sham-controlled trial. Individuals with OCD who had baseline YaleBrown obsessive-compulsive scale (Y-BOCS) of $>15$ were enrolled. Eligible cases were randomly assigned in 1:1 ratio to receive either 20-min-period of stimulation with tDCS and fluoxetine (experimental arm) or fluoxetine only (sham control arm). The anodal electrode of tDCS was placed over the left dorsolateral prefrontal cortex (Fp3) and the cathodal electrode was placed over the right orbitofrontal cortex (F8). Two mA electrical stimulation with the tDCS was used for 20 min in individuals of experimental group. In the control group, electrodes were placed and stimulation was administered for $30 \mathrm{~s}$ to induce the same skin sensation as in experimental group. This procedure was performed three times per week for 8 weeks. Y-BOCS test was assessed at baseline, week 4 (after 12th stimulation), week 8 (after 24th stimulation), and 1 month after the last stimulation. The primary endpoints were the mean changes in Y-BOCS total score from baseline to the last visit. The secondary endpoints were the mean changes in obsession and compulsion sub-scores from baseline to the last visit. Adverse events were also assessed. Mixed design repeated measures analysis of variance assessed the endpoints.
\end{abstract}

Results: Sixty individuals (30 in each group) were participated. All individuals in control group and 28 cases in experimental arm completed the trial. The mean Y-BOCS $\left(F_{(1.85)}=30.83 ; P<0.001\right)$, OCD obsession $\left(F_{(2.23)}=25.01\right.$; $P<0.001)$, and compulsion $\left(F_{(2.06)}=10.81 ; P<0.001\right)$ scores decreased significantly during the study. No statistical differences were, however, detected between experimental and control groups $(P>0.05)$. The tDCS was well tolerated and no major adverse events were reported.

(Continued on next page)

\footnotetext{
* Correspondence: Basalehi@yahoo.com

${ }^{5}$ Department of Psychiatry, Arak University of Medical Sciences, Arak, Iran

Full list of author information is available at the end of the article
}

C C The Author(s). 2020 Open Access This article is licensed under a Creative Commons Attribution 4.0 International License, which permits use, sharing, adaptation, distribution and reproduction in any medium or format, as long as you give appropriate credit to the original author(s) and the source, provide a link to the Creative Commons licence, and indicate if changes were made. The images or other third party material in this article are included in the article's Creative Commons licence, unless indicated otherwise in a credit line to the material. If material is not included in the article's Creative Commons licence and your intended use is not permitted by statutory regulation or exceeds the permitted use, you will need to obtain permission directly from the copyright holder. To view a copy of this licence, visit http://creativecommons.org/licenses/by/4.0/ The Creative Commons Public Domain Dedication waiver (http://creativecommons.org/publicdomain/zero/1.0/) applies to the data made available in this article, unless otherwise stated in a credit line to the data. 
(Continued from previous page)

Conclusion: This study showed that among individuals with moderate to severe OCD, there was no significant difference regarding OC symptoms between cases used tDCS as adjunctive therapy with fluoxetine and individuals used fluoxetine only.

Trial registration: IRCT2017030632904N1. Registered 14 July 2017, http://irct.ir/user/trial/44193/view

Keywords: Obsessive-compulsive disorder, Transcranial direct current stimulation, Fluoxetine, Yale-Brown obsessivecompulsive scale, Anxiety

\section{Background}

Obsessive-compulsive disorder (OCD) is a debilitating condition characterized by recurring, unwanted thoughts and ideas (obsessions) and behaviors (compulsions). The global prevalence of OCD is about 1 to $2 \%[1,2]$ and is more frequent among females [2]. Studies showed that OCD is associated with decreased levels of serotonin [35]. Selective serotonin re-uptake inhibitors (SSRIs) are, therefore, often used as the first-line treatment in OCD [6]. In non-responders, serotonin-norepinephrine reuptake inhibitors (e.g. venlafaxine), tricyclic antidepressants (e.g. clomipramine), and atypical antipsychotics (e.g. aripiprazole) are suggested for therapy. About 40 to $60 \%$ of people with OCD achieve remission with these pharmacotherapeutic options [7]. Cognitive-behavioral therapy (CBT), is also useful in individuals with OCD. Evidence showed that CBT is effective in more than one-third of people with OCD but they are at risk of relapse [8]. When mono-therapy is not effective, other approaches including "combining", "augmenting", and "switching" strategies can be used but they may not always provide adequate relief and may cause significant adverse events $[9,10]$. New therapeutic options are, therefore, needed.

Emerging evidence suggested that OCD was associated with impaired function in the fronto-striatal-thalamiccortical loop circuits including the dorsolateral prefrontal cortex (DLPFC), the orbitofrontal cortex, medial prefrontal cortex (e.g. anterior cyngulate gyrus), supplementary motor area, and the basal ganglia [11, 12]. A neuromodulatory method known as transcranial direct current stimulation (tDCS) showed promising results in several neuropsychiatric disorders [13-16]. Direct electrical stimulation of the brain over the skull is a noninvasive and safe method with minor side-effects. In tDCS, weak direct current ( 1 to $2 \mathrm{~mA}$ ) is applied to the scalp of subjects [17] that flows from the anode to the cathode with a fraction of the current entering the brain. The tDCS can cause more or fewer neurons to fire by alternating the excitability of neurons and shifting the membrane potential of superficial neurons to depolarize or hyperpolarize [18]. Some earlier uncontrolled and small sample-sized studies have shown that tDCS may improve symptoms of OCD [19-21]. This randomized clinical trial (RCT) was designed to evaluate the safety and clinical efficacy of tDCS as add-on therapy to fluoxetine in individuals with moderate to severe OCD. We hypothesized that improvements in obsessive compulsive symptoms by using tDCS as an adjunctive therapy with fluoxetine were not worse than using fluoxetine only (non-inferiority).

\section{Methods \\ Study design and sample}

This was a randomized double-blind sham-controlled trial conducted in Amir Kabir Hospital, affiliated to Arak University of Medical Sciences, Iran. Individuals aged 18 to 60 years with recent diagnosis of moderate to severe OCD based on DSM-V criteria [22] were included. To assess the severity of OCD, Yale-Brown obsessive compulsive scale (Y-BOCS) was used and cases with the baseline score above 15 were enrolled. Individuals with the history of any physical or psychiatric conditions but OCD or the history of substance use were excluded. Other exclusion criteria were taking monoamine oxidase inhibitors or antipsychotics for any reason; concurrent use of CBT; changes in the treatment regimen of OCD in the last 6 months; electroconvulsive therapy (ECT) during the last 6 months; pregnancy; no prior therapeutic response to SSRI, and the history of adverse events with SSRI use.

The trial was conducted according to the original protocol. The protocol of this study was reviewed and approved by the local ethics committee (IR.ARAKMU.REC.1395.9). Each subject received a full description of the study. Written informed consent was obtained from all subjects. The study was conducted with adherence to CONSORT guidelines and was registered prospectively with Iranian Registry of Clinical Trials, IRCT.ir; number: IRCT2017030632904N1.

\section{Randomization and masking}

Included participants were randomly assigned in 1:1 ratio via an interactive web response system to receive either tDCS and fluoxetine or fluoxetine only. Permuted block randomization method (block size $=4$ ) was used 
for group allocation. Participants and investigators were blinded during the study. Two individuals (a nurse and a medical doctor) were responsible to perform tDCS on participants. They were trained in the procedure of tDCS and were informed about the aim of the study. They were the only individuals who were not masked during the trial but they had no information regarding the clinical data of participants. They had no contacts with investigators and were monitored during the procedure so they did not reveal any information to participants. The responsible statistician was not aware of the clinical characteristics of subjects. All cases were connected to the tDCS via electrodes and electric current was administered to the sham control group for $30 \mathrm{~s}$ so the same sensation as in experimental group (tingling of skin) was induced. The electrodes were remained around the head of these cases for further $20 \mathrm{~min}$ without electrical stimulation.

\section{tDCS procedure}

Direct electrical stimulation was started with the tDCS device (manufactured by Medina Teb, Iran). Two electrodes (size: $7 \mathrm{~cm} \times 5 \mathrm{~cm}$ ) referenced as anode and cathode were used to deliver stimulation and were held around the head by non-conducting bandage. To minimize the noise pollution, the doors of recording room were closed during the experiment.

The anodal electrode generally increases (depolarize neurons) and the cathodal electrode decreases (hyperpolarize neurons) the cortical excitability [18]. Anodal stimulation of left DLPFC was shown to decrease the hyperactivity of Delta and Theta bands and normalize the electroencephalography (EEG) pattern of cases with OCD [23]. The anode electrode of tDCS device was, therefore, placed on the left DLPFC equivalent to $\mathrm{Fp} 3$ point of the international 10-20 EEG system. The cathode electrode was placed on the right lateral aspect of orbit (F8 point of the 10-20 EEG system) to target right orbitofrontal cortex (OFC). A current of $2 \mathrm{~mA}$ was set for stimulation. Prior to any electric stimulation, the skin surface was examined to assure the absence of burns, scratches, redness, pain, and inflammation. The electrodes were, then, covered in sponges soaked with $0.9 \%$ saline solution to prevent pain and burns during stimulation. Upon the patient's announcement of readiness, the electric current was exerted in a $20 \mathrm{~min}$-period in experimental group. Additional ramp up (15s) and ramp down (15 s) stimulation was administered at the beginning and end of the session; respectively. The current of $2 \mathrm{~mA}$ was used for $30 \mathrm{~s}$ in sham control arm. This procedure was performed three times per week for 8 weeks.
All patients received $20 \mathrm{mg}$ of fluoxetine twice each day. The dose of fluoxetine was not changed during the study period.

\section{Yale-Brown obsessive compulsive scale}

The scale was developed by Goodman et al. [24], and consists of 10 items (5 items to assess the obsessive thoughts and 5 items for compulsive behaviors). Each item can be scored on a 5-point scale (0-4). Severity, frequency, and duration of symptoms as well as trying to resist the symptoms and the affect of symptoms to interfere with everyday life of cases will be questioned in this test [24]. People with the diagnosis of OCD can be classified based on the total score of the test:

8 to 15 : mild; 16 to 23 : moderate; 24 to 31 : severe; 32 to 40: extreme.

The study on 40 patients showed that the reliability of Yale-Brown obsessive compulsive scale (Y-BOCS) was 0.98 and the internal consistency coefficient (alpha coefficient) was 0.89 [24]. The study on 140 cases with OCD indicated that the Farsi version of Y-BOCS had also satisfactory reliability and validity (internal consistency score of 0.97 for symptom checklist; internal consistency score of 0.95 for severity scale; and test-retest reliability of 0.99) [25].

\section{Clinical assessments}

At baseline, Demographic and clinical data were obtained by interviewing individuals. Clinical symptoms and Y-BOCS scores were measured at baseline and during follow-ups at week 4 (after 12th session), week 8 (after 24th session), and 1 month after the last session. The primary endpoints were the mean changes in Y-BOCS total score from baseline to the last follow-up visit. The secondary endpoints were the mean changes in Y-BOCS obsession and compulsion sub-scores from baseline to the last follow-up visit. Adverse events were also assessed. During the followup visits we asked the participants to report any side effects. A phone number was also provided so the cases could ask their questions or report any side effects as soon as possible. Participants were requested to visit the emergency department if a major complication happened. A list of common adverse events of SSRI and tDCS was also provided so the cases were aware of those conditions. The interview and procedures were all performed in a calm and stress-free situation for the examiner and participants.

\section{Statistical data analysis}

When this study was designed in 2017, no similar placebo-controlled study was available. Therefore, we assumed effect size as $0.15(\mathrm{~F}=0.15)$ to calculate the sample size (statistical test: repeated measures, within- 
between interaction). Considering $\alpha$ (the probability of type I error) as 0.05 and $\beta$ (the probability of type II error) as 0.20 , the required total sample size was 60 (30 participants per group). G*Power software was used for sample size calculation.

Data were analyzed by IBM SPSS Software, version 25.0 (SPSS Inc., Chicago, IL). Descriptive statistics (mean and SD, or number and \%) were used to express demographic and clinical data. The normality of data were examined using Kolmogorov-Smirnov test. Baseline characteristics were compared between groups using chi-square tests for categorical variables and independent sample t-tests for numeric variables. Mixed design repeated measures analysis of variance (ANOVA) with terms for group, time, and time*group interaction was used to evaluate changes in outcome measures during the study period. Cohen's $d$ test with 95\% confidence interval (CI) were used to measure the effect sizes that were classified as small (d: 0 to $0.20)$, medium (d: 0.20 to 0.50$)$, and large $(\mathrm{d}>0.50)$. Two-tailed $p$-values $<0.05$ were considered statistically significant.

\section{Results}

\section{Baseline characteristics}

The trial started on March 21, 2017, when the recruitment of participants with OCD was begun. The double-blind treatment was given from May 2, 2017, when the first individual was assigned to July 23, 2018. A total of 60 individuals were randomly assigned to tDCS $(n=30)$ and sham control $(n=30)$ groups. All participants completed 24 sessions of the allocated treatment. Two individuals in tDCS arm were lost for the last follow-up visit. None of these missed participants reported adverse events. Overall, 28 individuals in the tDCS group and all participants in the sham control arm completed the study (Fig. 1). The baseline clinical and demographic characteristics of participants are described in Table 1. No statistical differences were observed between two arms of study regarding baseline characteristics.

\section{Clinical outcomes}

Clinical measures at each study point are summarized in Table 2. The mixed design repeated-measures ANOVA for the total Y-BOCS score revealed a significant time effect $\left(\mathrm{F}_{(1.85)}=30.83 ; P<0.001\right)$ but no significant group effect $\left(\mathrm{F}_{(1.00)}=0.07 ; P=0.799\right)$ or interaction between time and group effect were observed $\left(\mathrm{F}_{(1.85)}=0.86 ; P=\right.$ 0.420) (Fig. 2). The Cohen's $d$ test for the Y-BOCS means at the last follow-up visit showed d: 0.079 with 95\%CI: -0.446 to 0.604 .

Our study also showed that Y-BOCS obsession and compulsion scores decreased significantly during the study period $\left(\mathrm{F}_{(2.23)}=25.01 ; P<0.001\right.$ and $\mathrm{F}_{(2.06)}=10.81$; $P<0.001$, respectively). No significant time"group

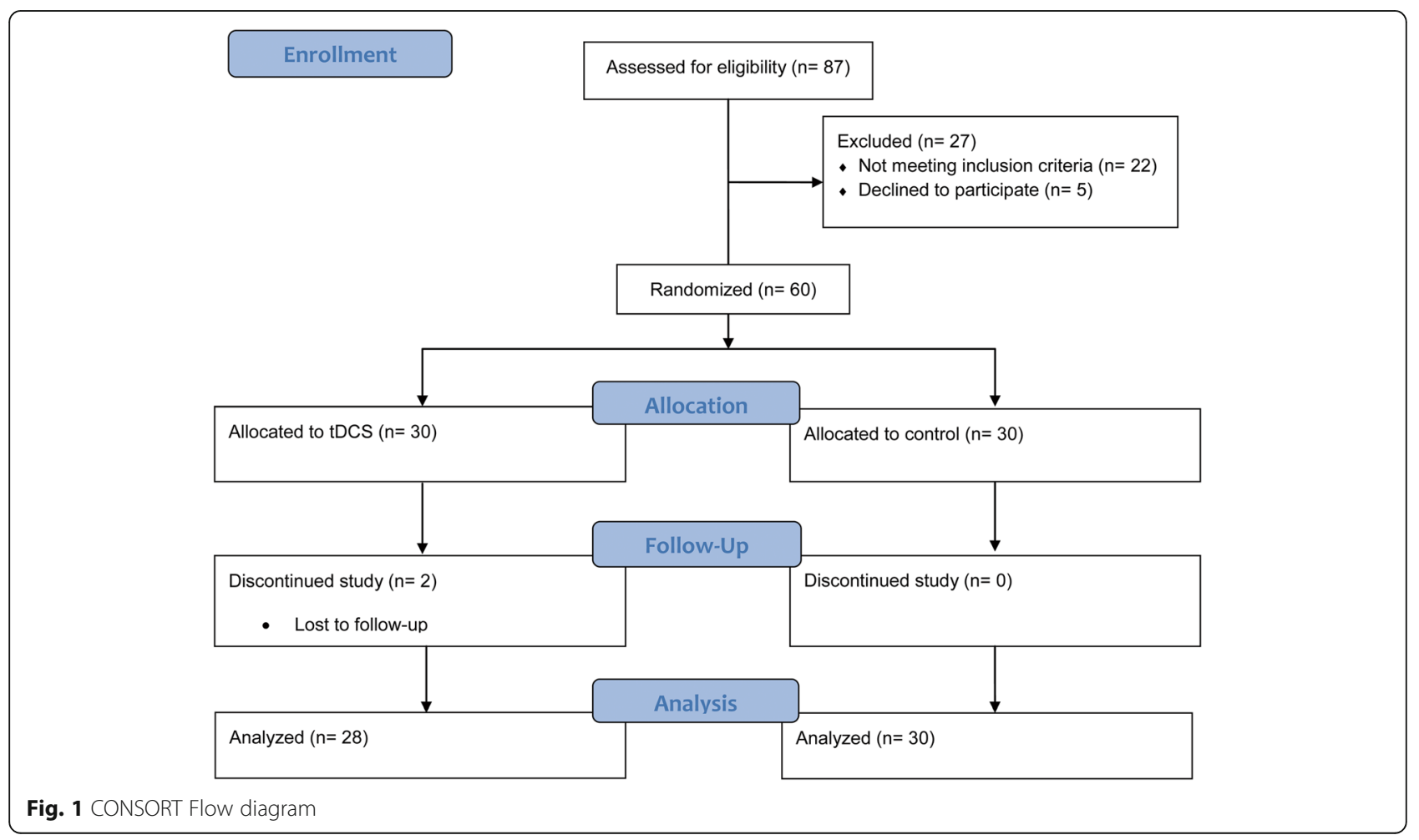


Table 1 Baseline clinical and socio-demographical characteristics of the recruited patients with OCD

\begin{tabular}{|c|c|c|c|}
\hline & $\operatorname{tDCS}(n=30)$ & Control $(n=30)$ & P-value \\
\hline Age, year $[$ mean $\pm S D]$ & $38.6 \pm 12.6$ & $35.9 \pm 11.5$ & 0.395 \\
\hline Gender, male $[\mathrm{n}(\%)]$ & $4(13.3)$ & $7(23.3)$ & 0.506 \\
\hline Marital status [n (\%)] & & & 0.379 \\
\hline Single & $10(33.3)$ & $15(50.0)$ & \\
\hline Married & $19(63.3)$ & $13(43.3)$ & \\
\hline Divorced & $1(3.3)$ & $2(6.7)$ & \\
\hline Education [n (\%)] & & & 0.999 \\
\hline Under diploma & $10(33.3)$ & $10(33.3)$ & \\
\hline Diploma & $13(43.3)$ & $14(46.7)$ & \\
\hline Bachelor's & $7(23.3)$ & $6(20.0)$ & \\
\hline Occupation [n (\%)] & & & 0.312 \\
\hline Housekeeper & $19(63.3)$ & $13(43.3)$ & \\
\hline Employed & $3(10.0)$ & $6(20.0)$ & \\
\hline Unemployed & $8(26.7)$ & $11(36.7)$ & \\
\hline Smoking [n (\%)] & $2(6.7)$ & $0(0.0)$ & 0.492 \\
\hline Family history of psychiatric illness [n (\%)] & & & 0.7 \\
\hline Depression & $1(3.3)$ & $3(10.0)$ & \\
\hline ADHD & $1(3.3)$ & $0(0.0)$ & \\
\hline Bipolar disorder & $2(6.7)$ & $1(3.3)$ & \\
\hline OCD & $11(36.7)$ & $13(43.3)$ & \\
\hline Socioeconomic status [n (\%)] & & & 0.205 \\
\hline Very low & $4(15.4)$ & $6(20.7)$ & \\
\hline Low & $6(23.1)$ & $9(31.0)$ & \\
\hline Moderate & $7(26.9)$ & $11(37.9)$ & \\
\hline High & $9(34.6)$ & $3(10.3)$ & \\
\hline Hospitalization [n (\%)] & $6(20.0)$ & $7(23.3)$ & 0.754 \\
\hline
\end{tabular}

$A D H D$ attention deficit hyperactivity disorder; $O C D$ obsessive-compulsive disorder

interaction was, however, detected for Y-BOCS obsession $\left(\mathrm{F}_{(1.85)}=0.68 ; P=0.523\right)$ and compulsion $\left(\mathrm{F}_{(2.06)}=\right.$ $0.147 ; P=0.869)$ scores. The Cohen's $d$ test at the last follow-up visit showed d: 0.029 with $95 \% \mathrm{CI}:-0.496$ to 0.555 for obsession mean scores and d: 0.119 with 95\%CI: -0.405 to 0.644 for compulsion mean scores.

Regarding safety endpoint, tDCS stimulation was well tolerated and no serious adverse events were reported. No cases left the study due to adverse events. Eight individuals in the tDCS group experienced minor adverse events (redness: 2 and irritation: 6). No adverse event occurred in the control group.

\section{Discussion}

Our trial showed that individuals with moderate to severe $\mathrm{OCD}$ in the experimental group (tDCS stimulation + fluoxetine) had about $23 \%$ improvements in OC symptoms using Y-BOCS scale. Participants in sham controlled arm had about $22 \%$ improvements in symptoms.
There was no statistical significant difference between two groups.

The lack of significant difference between groups might be partialy explained by tDCS parameters used in this trial. The most appropriate tDCS protocol regarding the electrode placement and the current delivered via electrodes are not well-established. The higher current dosage and longer sessions that were used in other psychiatric disorders might improve OC symptoms significantly [26]. Anodal electrode was placed over DLPFC in the present study. It was reported that DLPFC (Brodmann areas: 9 and 46) was associated with executive functions including working memory, selective attention, and maintaining or shifting sets in response to changing task demands [27]. The hypoactivation of DLPFC was observed in individuals with OCD [28]. Study on deep brain stimulation of cases with refractory OCD reported that DLPFC activation was associated with excellent clinical effects [29]. The cathodal electrode was placed 
Table 2 Clinical measures

\begin{tabular}{|c|c|c|c|c|c|c|c|c|c|c|c|}
\hline & \multicolumn{4}{|c|}{$\operatorname{tDCS}(n=28)$} & \multicolumn{4}{|c|}{ Control $(n=30)$} & \multirow{2}{*}{$\begin{array}{l}\text { ANOVA } \\
\text { (time) }\end{array}$} & \multirow{2}{*}{$\begin{array}{l}\text { ANOVA } \\
\text { (time* group) }\end{array}$} & \multirow{2}{*}{$\begin{array}{l}\text { ANOVA } \\
\text { (group) }\end{array}$} \\
\hline & Baseline & S12 & S24 & M1 & Baseline & S12 & S24 & M1 & & & \\
\hline $\begin{array}{l}\text { Y-BOCS } \\
\text { total }\end{array}$ & $29.8 \pm 6.6$ & $25.0 \pm 8.2$ & $21.7 \pm 9.5$ & $22.9 \pm 10.0$ & $28.1 \pm 5.7$ & $24.8 \pm 7.1$ & $22.4 \pm 8.9$ & $21.9 \pm 10.3$ & $\begin{array}{l}F_{(1.85)}= \\
30.83 ; P< \\
0.001\end{array}$ & $\begin{array}{l}F_{(1.85)}=0.86 \\
P=0.420\end{array}$ & $\begin{array}{l}F_{(1.00)}= \\
0.07 ; P= \\
0.799\end{array}$ \\
\hline $\begin{array}{l}\text { Y-BOCS } \\
\text { obsession }\end{array}$ & $15.2 \pm 3.7$ & $14.1 \pm 3.5$ & $11.1 \pm 4.6$ & $11.5 \pm 5.0$ & $14.1 \pm 3.5$ & $12.3 \pm 4.4$ & $11.1 \pm 4.5$ & $11.3 \pm 5.4$ & $\begin{array}{l}\mathrm{F}_{(2.23)}= \\
25.01 ; P< \\
0.001\end{array}$ & $\begin{array}{l}F_{(1.85)}=0.68 \\
P=0.523\end{array}$ & $\begin{array}{l}F_{(1.00)}= \\
0.10 ; P= \\
0.748\end{array}$ \\
\hline $\begin{array}{l}\text { Y-BOCS } \\
\text { compulsion }\end{array}$ & $14.3 \pm 3.7$ & $12.5 \pm 4.8$ & $11.7 \pm 8.7$ & $11.4 \pm 5.3$ & $14.0 \pm 3.1$ & $12.5 \pm 3.7$ & $11.3 \pm 5.0$ & $10.6 \pm 5.5$ & $\begin{array}{l}\mathrm{F}_{(2.06)}= \\
10.81 ; P< \\
0.001\end{array}$ & $\begin{array}{l}F_{(2.06)}=0.147 \\
P=0.869\end{array}$ & $\begin{array}{l}F_{(1.00)}= \\
0.10 ; P= \\
0.748\end{array}$ \\
\hline
\end{tabular}

Y-BOCS Yale-Brown Obsessive and Compulsive Scale; S12 session 12; S24 session 24; M1 1 month after the last session

over OFC in this trial. This cortical area was found to be hyperactive in most individuals with OCD [30] and successful treatments could normalize its function [31].

Different case-report studies assessed the efficacy of tDCS stimulation on individuals with OCD (Table 3). The results of these studies were inconsistent with each other. One study with one OCD case showed that tDCS stimulation was not associated with significant improvements in symptoms [32]. Another study with two participants indicated that one case had over $15 \%$ improvements with tDCS stimulation but the second individual had no statistical significant improvement [33]. Over 20 to $60 \%$ decrease in symptoms was observed in other studies [34-39]. We also found 3 non-randomized open label trials with small sample sizes (Table 3). These studies showed that tDCS was effective to improve OC symptoms compared to baseline [20, 40, 41].

Four randomized clinical trials assessed the efficacy of tDCS on people with OCD (Table 3) [21, 42-44]. A randomized double-blind sham controlled study suggested that $\mathrm{tDCS}$ could be effective in people with moderate to severe OCD $(\mathrm{Y}-\mathrm{BOCS}>16)$ who were resistant to SSRI

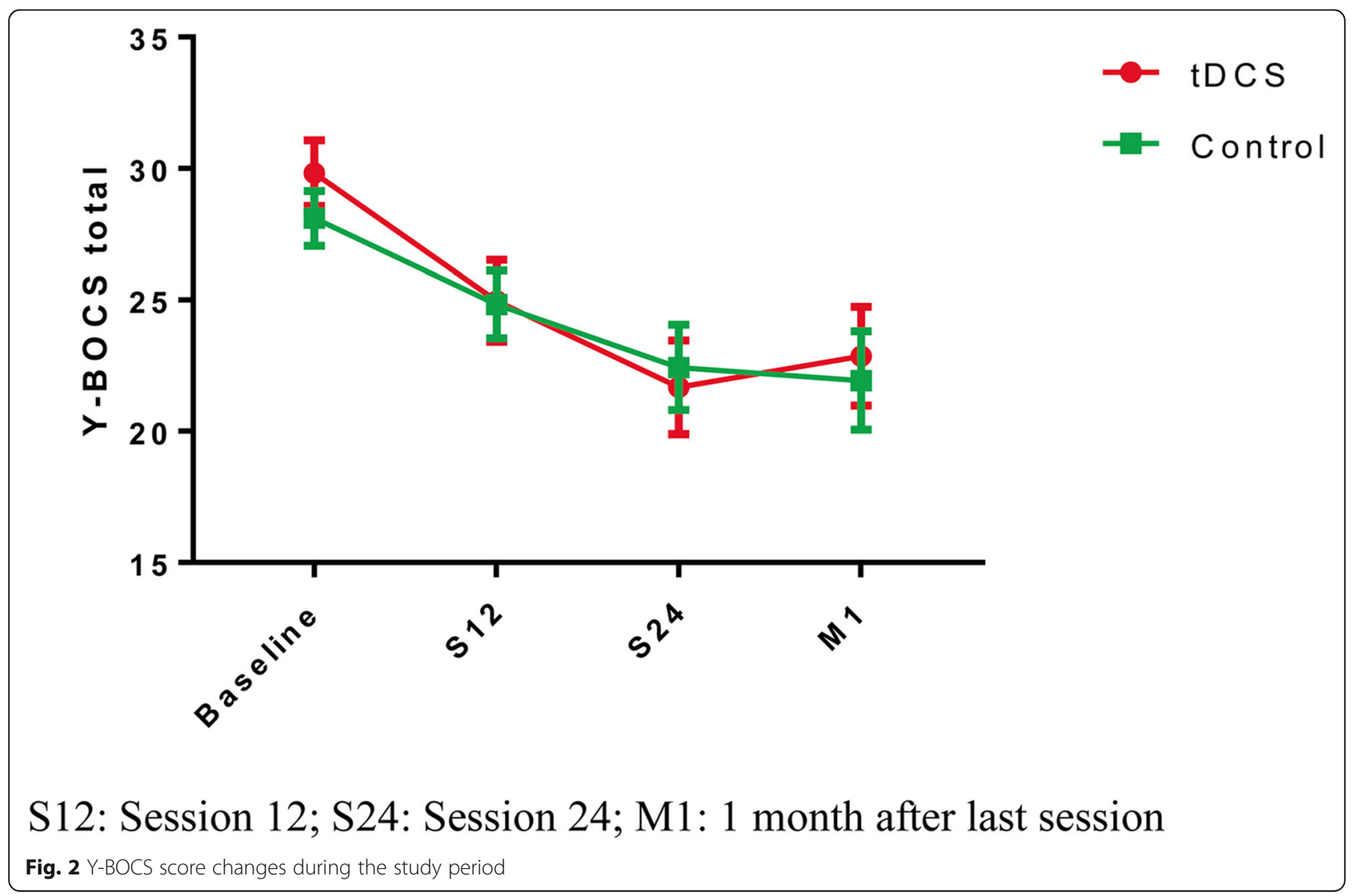


Table 3 Studies investigated the efficacy of tDCS on individuals with OCD

\begin{tabular}{|c|c|c|c|}
\hline Author, year & Study design & Anode and cathode position & Results \\
\hline $\begin{array}{l}\text { Volpato et al., } \\
2013 \text { [32] }\end{array}$ & $\begin{array}{l}\text { Case report } \\
\text { One } 35 \text { year-old-male }\end{array}$ & $\begin{array}{l}\text { Anode: neck; Cathode: F3 } \\
2 \mathrm{~mA}, 20 \text { min daily for } 10 \text { days }\end{array}$ & $\begin{array}{l}\text { - Not effective on OC symptoms } \\
\text { - Significant effect on depression and anxiety }\end{array}$ \\
\hline $\begin{array}{l}\text { Silva et al., } 2016 \\
\text { [33] }\end{array}$ & $\begin{array}{l}\text { Case report } \\
\text { Two } 31 \text { and } 37 \text { year-old- } \\
\text { males }\end{array}$ & $\begin{array}{l}\text { Anode: left deltoid muscle; Cathode: pre- } \\
\text { SMA } \\
2 \text { mA, } 30 \text { min daily for } 20 \text { days }\end{array}$ & $\begin{array}{l}\text { - One participant had no improvement in Y-BOCS, depres- } \\
\text { sion, and anxiety } \\
\text { - One participant had } 55 \% \text { reduction in Y-BOCS and 50\% re- } \\
\text { duction in depression and anxiety symptoms }\end{array}$ \\
\hline $\begin{array}{l}\text { Mondino et al., } \\
2015 \text { [34] }\end{array}$ & $\begin{array}{l}\text { Case report } \\
\text { One } 52 \text { year-old-female }\end{array}$ & $\begin{array}{l}\text { Anode: right occipital cortex; Cathode: } \\
\text { FP1 } \\
2 \mathrm{~mA}, 20 \text { min twice a day for } 5 \text { days }\end{array}$ & - $26 \%$ reduction in Y-BOCS \\
\hline $\begin{array}{l}\text { Narayanaswamy } \\
\text { et al., } 2015 \text { [35] }\end{array}$ & $\begin{array}{l}\text { Case report } \\
\text { One } 39 \text { year-old-female } \\
\text { and one } 24 \text { year-old- } \\
\text { male }\end{array}$ & $\begin{array}{l}\text { Anode: left pre-SMA; } \\
\text { Cathode: right supra-orbital area } \\
2 \mathrm{~mA}, 20 \text { min twice a day for } 10 \text { days }\end{array}$ & $\begin{array}{l}\cdot 46.7 \% \text { reduction in Y-BOCS of male } \\
\cdot 52 \% \text { reduction in Y-BOCS of female }\end{array}$ \\
\hline $\begin{array}{l}\text { D'Urso et al., } \\
2016 \text { [36] }\end{array}$ & $\begin{array}{l}\text { Case report } \\
\text { One } 33 \text { year-old-female }\end{array}$ & $\begin{array}{l}\text { Active: pre-SMA; } \\
\text { Reference: right deltoid } \\
2 \mathrm{~mA}, 20 \text { min daily for } 20 \text { days }\end{array}$ & $\begin{array}{l}\cdot 11 \% \text { worsening in Y-BOCS after anodal sessions } \\
\cdot 30 \% \text { reduction in Y-BOCS after cathodal sessions }\end{array}$ \\
\hline $\begin{array}{l}\text { Alizadeh } \\
\text { Goradel et al., } \\
2016[37]\end{array}$ & $\begin{array}{l}\text { Case report } \\
\text { One } 23 \text { year-old-female }\end{array}$ & $\begin{array}{l}\text { Anode: } \mathrm{O} 2 \text {; Cathode: left OFC } \\
2 \mathrm{~mA}, 20 \text { min daily for } 10 \text { days }\end{array}$ & $\begin{array}{l}\text { - } 64 \% \text { reduction in Y-BOCS; } 87 \% \text { reduction in depression; and } \\
100 \% \text { reduction in anxiety symptoms }\end{array}$ \\
\hline $\begin{array}{l}\text { Palm et al., } 2017 \\
\text { [38] }\end{array}$ & $\begin{array}{l}\text { Case report } \\
\text { One } 31 \text { year-old-male }\end{array}$ & $\begin{array}{l}\text { Anode: F3; } \\
\text { Cathode: F4 } \\
2 \text { mA, } 30 \text { min twice a day with total } 20 \\
\text { stimulations in } 2 \text { weeks }\end{array}$ & - $22 \%$ reduction in Y-BOCS \\
\hline $\begin{array}{l}\text { Hazari et al., } \\
2016[39]\end{array}$ & $\begin{array}{l}\text { Case report } \\
\text { One } 24 \text { year-old-male }\end{array}$ & $\begin{array}{l}\text { Anode: left pre-SMA; } \\
\text { Cathode: right supraorbital area } 2 \text { mA, } 20 \\
\text { min twice a day for } 10 \text { days }\end{array}$ & - $80 \%$ reduction in Y-BOCS \\
\hline $\begin{array}{l}\text { Dinn et al., } 2016 \\
\text { [40] }\end{array}$ & $\begin{array}{l}\text { Open label trial } \\
\text { Four females and one } \\
\text { male }\end{array}$ & $\begin{array}{l}\text { Anode: F3; Cathode: Fp2 } \\
2 \mathrm{~mA}, 20 \text { min daily for } 15 \text { days }\end{array}$ & $\begin{array}{l}\text { - } 23 \% \text { reduction in Y-BOCS but was not maintained at } 1 \\
\text { month of follow-up } \\
\text { - No reduction in anxiety symptoms and 30\% reduction in } \\
\text { depression symptoms }\end{array}$ \\
\hline $\begin{array}{l}\text { Najafi et al., } \\
2017 \text { [41] }\end{array}$ & $\begin{array}{l}\text { Open label trial } \\
\text { Twenty three females } \\
\text { and nineteen males }\end{array}$ & $\begin{array}{l}\text { Anode: P1, C3, T7; Cathode: Fp2 } \\
2 \text { mA, } 30 \text { min daily with total } 15 \\
\text { stimulations in } 3 \text { weeks }\end{array}$ & - $79 \%$ reduction in Y-BOCS \\
\hline $\begin{array}{l}\text { Bation et al., } \\
2016 \text { [20] }\end{array}$ & $\begin{array}{l}\text { Open label trial } \\
\text { Six females and two } \\
\text { males }\end{array}$ & $\begin{array}{l}\text { Anode: right } \\
\text { cerebellum; } \\
\text { Cathode: left OFC } \\
2 \mathrm{~mA}, 20 \text { min twice a day for } 5 \text { days }\end{array}$ & - $26 \%$ reduction in $Y-O B C S$ \\
\hline $\begin{array}{l}\text { D'Urso et al., } \\
2016 \text { [21] }\end{array}$ & $\begin{array}{l}\text { RCT } \\
\text { Seven females and four } \\
\text { males }\end{array}$ & $\begin{array}{l}\text { Active: } \mathrm{Cz} \text {; Reference: lateral surface of } \\
\text { right deltoid } \\
2 \mathrm{~mA}, 20 \text { min daily for } 10 \text { days }\end{array}$ & $\begin{array}{l}\text { - Cases with anodal stimulation }(N=6) \text { had worsening in } Y \text { - } \\
\text { BOCS } \\
\text { - Cases with cathodal stimulation }(N=6) \text { had } 20 \% \text { reduction } \\
\text { in Y-BOCS }\end{array}$ \\
\hline $\begin{array}{l}\text { Yekta et al., } 2015 \\
\text { [42] }\end{array}$ & $\begin{array}{l}\text { Controlled RCT } \\
\text { Twenty cases (no data } \\
\text { on gender) }\end{array}$ & $\begin{array}{l}\text { Anode: } F 4 \text {; Cathode: } F 3 \\
2 \text { mA; } 20 \text { min daily for } 15 \text { days in } \\
\text { experimental group }\end{array}$ & $\begin{array}{l}\text { - Improved decision-making of experimental group }(N=10) \\
\text { compared to sham control group }(N=10) \\
\text { - No report on Y-BOCS }\end{array}$ \\
\hline $\begin{array}{l}\text { Gowda et al., } \\
2019 \text { [43]; }\end{array}$ & $\begin{array}{l}\text { Controlled RCT } \\
\text { Four females and } 21 \\
\text { males }\end{array}$ & $\begin{array}{l}\text { Anode: pre-SMA; Cathode: right supra- } \\
\text { orbital area } 2 \text { mA, } 20 \text { min twice a day for } \\
5 \text { days }\end{array}$ & $\begin{array}{l}\text { - Y-BOCS was significantly reduced in experimental group } \\
\text { compared to baseline and sham control arm }\end{array}$ \\
\hline $\begin{array}{l}\text { Bation et al., } \\
2020 \text { [44]; }\end{array}$ & Controlled RCT & $\begin{array}{l}\text { Anode: right cerebellum; Cathode: PF1 } \\
2 \mathrm{~mA}, 20 \text { min twice a day for } 5 \text { days }\end{array}$ & $\begin{array}{l}\text { - Significant acute effect of tDCS in experimental group } \\
\text { compared to baseline and sham control arm } \\
\text { - No changes in experimental group was observed } \\
\text { compared to sham control arm after } 1 \text { and } 3 \text { months of } \\
\text { tDCS stimulation }\end{array}$ \\
\hline
\end{tabular}

therapy [43]. Another recent RCT with sham controlled arm showed the significant acute effect of tDCS on individuals with OCD compared with control arm but did not find any statistical difference between groups in 1 and 3 months after treatment [44]. Discrepancies in results of these trials can be due to the methodological differences and small sample sizes. The cathodal and anodal placements in these studies were different to each 
other and to the present study. Furthermore, none of the above-mentioned trials assessed the efficacy of tDCS as add-on therapy.

\section{Strengths, limitations, and future directions}

Randomization, blinding, and the presence of sham controlled arm were the major strengths of this study. The prospective population-based approach was another important strength of our trial that can increase the external validity of the reported results. Small sample size and short periods of follow-up were main limitations of trial. OC symptoms cannot be objectively evaluated and our outcomes were reliant on the reports of individuals using Y-BOCS test. This can lead to measurement bias (hawthorne effect). The cathodal stimulation with tDCS on individuals with OCD was shown to be effective in case-report studies more than anodal stimulation. Future controlled RCTs should investigate this hypothesis. Further studies with higher number of cases should also evaluate the efficacy of tDCS as the only therapy on improvements of OC symptoms in cases with different severity.

\section{Conclusions}

The tDCS adjunctive therapy with the anode placed over left DLPFC and cathode placed over right OFC was generally safe and a tolerable procedure. This study didn't show significant clinical efficacy of add-on therapy with tDCS in the management of individuals with moderate to severe OCD compared to the control group.

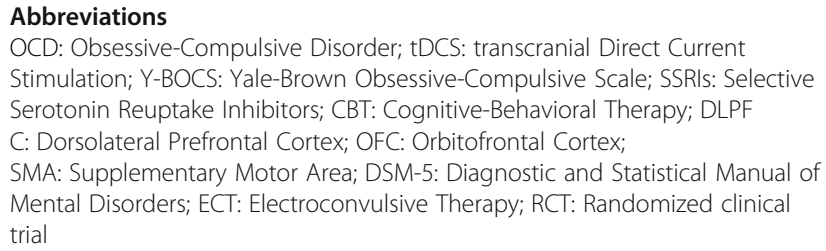

\section{Acknowledgements}

We would like to express our gratitude for the department of psychiatry, faculty of medicine, Arak University of Medical Sciences.

\section{Authors' contributions}

SY and BS conducted the study design, obtaining funding, statistical analysis of data, interpretation of data, manuscript writing, final proof reading before submission, and supervision of progress of the study. MA and MS did the manuscript writing and revised the statistical analysis. SVM revised the statistical analyses. JB and VS conducted Y-BOCS and tDCS. AY supervised the tDCS, interpretation of data and writing the first draft of the manuscript. All authors read and approved the final manuscript.

\section{Funding}

BS completed this work as a associate professor in psychiatry department at Amirkabir hospital, as a clinical trial on the study of the effect of Transcranial Direct Current Stimulation as an adjunct to Fluoxetine for ObsessiveCompulsive Disorder, funded by Arak university of medical sciences (project number 1143). The funders had no role in study design, data collection, data analysis, interpretation of data, or writing the manuscript.

\section{Availability of data and materials}

The datasets generated and/or analysed during the current study are not publicly available but are available from the corresponding author on reasonable request.

\section{Ethics approval and consent to participate}

The procedures were fully explained to the patients, and an informed consent form was taken. Every stage of research were performed according to Helsinki ethical statements. Patients were allowed to withdraw whenever they wished. Written consent was obtained from the participant as mentioned in method section. The project was approved by the Ethical Committee of Arak University of Medical Sciences (12-140-91). Moreover, it was registered in clinical trial system with code: IRCT2017030632904N1.

\section{Consent for publication}

Not applicable.

\section{Competing interests}

The authors declare that they have no competing interests.

\section{Author details}

${ }^{1}$ Neurosciences Research Center, Qom University of Medical Sciences, Qom, Iran. ${ }^{2}$ Spiritual Health Research Center, Qom University of Medical Sciences, Qom, Iran. ${ }^{3}$ Faculty of Medicine, Students' Scientific Research Center, Tehran University of Medical Sciences, Tehran, Iran. ${ }^{4}$ Neurolmmunology Research Association (NIRA), Universal Scientific Education and Research Network (USERN), Tehran, Iran. ${ }^{5}$ Department of Psychiatry, Arak University of Medical Sciences, Arak, Iran. ${ }^{6}$ Department of Neurosciences, School of Advanced Technologies in Medicine, Tehran University of Medical Sciences, Tehran, Iran.

Received: 22 December 2019 Accepted: 22 November 2020

Published online: 30 November 2020

\section{References}

1. Sasson Y, Zohar J, Chopra M, Lustig M, lancu I, Hendler T. Epidemiology of obsessive-compulsive disorder: a world view. J Clinical Psychiatry. 1997.

2. Franklin ME, Foa EB. Treatment of obsessive compulsive disorder. Annu Rev Clin Psychol. 2011;7:229-43.

3. Yaryura-Tobias J, Neziroglu F. The action of chlorimipramine in obsessivecompulsive neurosis: a pilot study. Curr Ther Res. 1975;17:111-6.

4. Goodman WK, Price LH, Delgado PL, Palumbo J, Krystal JH, Nagy LM, Rasmussen SA, Heninger GR, Charney DS. Specificity of serotonin reuptake inhibitors in the treatment of obsessive-compulsive disorder: comparison of fluvoxamine and desipramine. Arch Gen Psychiatry. 1990;47(6):577-85.

5. Katz R, DeVeaugh-Geiss J, Landau P. Clomipramine in obsessive-compulsive disorder. Biol Psychiatry. 1990;28(5):401-14.

6. Soomro GM. Obsessive compulsive disorder. BMJ Clinical Evidence. 2012; 2012.

7. Pallanti S, Hollander E, Bienstock C, Koran L, Leckman J, Marazziti D, Pato M, Stein D, Zohar J. Treatment non-response in OCD: methodological issues and operational definitions. Int J Neuropsychopharmacol. 2002;5(2):181-91.

8. Simpson HB, Huppert JD, Petkova E, Foa EB, Liebowitz MR. Response versus remission in obsessive-compulsive disorder. J Clinical Psychiatry. 2006.

9. Rabinowitz I, Baruch Y, Barak Y. High-dose escitalopram for the treatment of obsessive-compulsive disorder. Int Clin Psychopharmacol. 2008;23(1):49-53.

10. Matsunaga H, Nagata T, Hayashida K, Ohya K, Kiriike N, Stein DJ. A longterm trial of the effectiveness and safety of atypical antipsychotic agents in augmenting SSRI-refractory obsessive-compulsive disorder. J Clin Psychiatry. 2009;70(6):863-8.

11. Shah DB, Pesiridou A, Baltuch GH, Malone DA, O'Reardon JP. Functional neurosurgery in the treatment of severe obsessive compulsive disorder and major depression: overview of disease circuits and therapeutic targeting for the clinician. Psychiatry (Edgmont). 2008;5(9):24.

12. Berlim MT, Neufeld NH, Van den Eynde F. Repetitive transcranial magnetic stimulation (rTMS) for obsessive-compulsive disorder (OCD): an exploratory meta-analysis of randomized and sham-controlled trials. J Psychiatr Res. 2013;47(8):999-1006

13. Tortella G, Casati R, Aparicio LV, Mantovani A, Senço N, D’Urso G, Brunelin J, Guarienti F, Selingardi PML, Muszkat D. Transcranial direct current stimulation in psychiatric disorders. World J psychiatry. 2015;5(1):88. 
14. Fregni F, Boggio PS, Nitsche MA, Marcolin MA, Rigonatti SP, Pascual-Leone A. Treatment of major depression with transcranial direct current stimulation. Bipolar Disord. 2006;8(2):203-4.

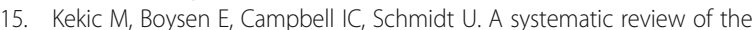
clinical efficacy of transcranial direct current stimulation (tDCS) in psychiatric disorders. J Psychiatr Res. 2016;74:70-86.

16. Szymkowicz SM, McLaren ME, Suryadevara U, Woods AJ. Transcranial direct current stimulation use in the treatment of neuropsychiatric disorders: a brief review. Psychiatr Ann. 2016;46(11):642-6.

17. Shafi MM, Westover MB, Fox MD, Pascual-Leone A. Exploration and modulation of brain network interactions with noninvasive brain stimulation in combination with neuroimaging. Eur J Neurosci. 2012;35(6):805-25.

18. Nitsche MA, Paulus W. Excitability changes induced in the human motor cortex by weak transcranial direct current stimulation. J Physiol. 2000;527(3): 633-9.

19. Palm U, Brunelin J, Wulf L, Mondino M, Brunoni A, Padberg F. Transcranial direct current stimulation (tDCS) for obsessive-compulsive disorder: a new treatment option? Fortschritte der Neurologie-Psychiatrie; 2018.

20. Bation R, Poulet E, Haesebaert F, Saoud M, Brunelin J. Transcranial direct current stimulation in treatment-resistant obsessive-compulsive disorder: an open-label pilot study. Prog Neuro-Psychopharmacol Biol Psychiatry. 2016; 65:153-7.

21. D'urso G, Brunoni AR, Mazzaferro MP, Anastasia A, de Bartolomeis A Mantovani A. Transcranial direct current stimulation for obsessivecompulsive disorder: a randomized, controlled, partial crossover trial. Depression and anxiety. 2016;33(12):1132-40.

22. Association AP: Diagnostic and statistical manual of mental disorders (DSM$\left.5^{\oplus}\right)$ : American psychiatric pub; 2013

23. Ghaffari H, Yoonessi A, Darvishi MJ, Ahmadi A. Normal electrical activity of the brain in obsessive-compulsive patients after anodal stimulation of the left dorsolateral prefrontal cortex. Basic and clinical neuroscience. 2018;9(2): 135.

24. Goodman WK, Price LH, Rasmussen SA, Mazure C, Fleischmann RL, Hill CL, Heninger GR, Charney DS. The Yale-Brown obsessive compulsive scale: I. development, use, and reliability. Arch Gen Psychiatry. 1989;46(11):1006-11.

25. Esfahani SR, Motaghipour Y, Kamkari K, Zahiredin A, Janbozorgi M. Reliability and validity of the Persian version of the Yale-Brown obsessive-compulsive scale (Y-BOCS). Iran J Psychiatry Clinical Psychol. 2012;17(4):297-303.

26. Senço NM, Huang Y, D'Urso G, Parra LC, Bikson M, Mantovani A, Shavitt RG, Hoexter MQ, Miguel EC, Brunoni AR. Transcranial direct current stimulation in obsessive-compulsive disorder: emerging clinical evidence and considerations for optimal montage of electrodes. Expert Rev Med Devices. 2015;12(4):381-91.

27. Bonelli RM, Cummings JL. Frontal-subcortical circuitry and behavior. Dialogues Clin Neurosci. 2007;9(2):141-51.

28. Karas PJ, Lee S, Jimenez-Shahed J, Goodman WK, Viswanathan A, Sheth SA. Deep brain stimulation for obsessive compulsive disorder: evolution of surgical stimulation target parallels changing model of dysfunctional brain circuits. Front Neurosci. 2019;12:998

29. Hartmann CJ, Lujan JL, Chaturvedi A, Goodman WK, Okun MS, Mclntyre CC, Haq IU. Tractography activation patterns in dorsolateral prefrontal cortex suggest better clinical responses in OCD DBS. Front Neurosci. 2016;9:519.

30. Ursu S, Carter CS. An initial investigation of the orbitofrontal cortex hyperactivity in obsessive-compulsive disorder: exaggerated representations of anticipated aversive events? Neuropsychologia. 2009;47(10):2145-8.

31. Rauch SL, Shin LM, Dougherty DD, Alpert NM, Fischman AJ, Jenike MA. Predictors of fluvoxamine response in contamination-related obsessive compulsive disorder: a PET symptom provocation study. Neuropsychopharmacology. 2002;27(5):782-91.

32. Volpato C, Piccione F, Cavinato M, Duzzi D, Schiff S, Foscolo L, Venneri A. Modulation of affective symptoms and resting state activity by brain stimulation in a treatment-resistant case of obsessive-compulsive disorder. Neurocase. 2013;19(4):360-70.

33. Silva RD, Brunoni AR, Miguel EC, Shavitt RG. Transcranial direct current stimulation for treatment-resistant obsessive-compulsive disorder: report on two cases and proposal for a randomized, sham-controlled trial. Sao Paulo medical journal. 2016;134(5):446-50.

34. Mondino M, Haesebaert F, Poulet E, Saoud M, Brunelin J. Efficacy of cathodal transcranial direct current stimulation over the left orbitofrontal cortex in a patient with treatment-resistant obsessive-compulsive disorder. Journal of ECT. 2015;31(4):271-2.
35. Narayanaswamy JC, Jose D, Chhabra H, Agarwal SM, Shrinivasa B, Hegde A, Bose A, Kalmady SV, Venkatasubramanian G, Reddy YJ. Successful application of add-on transcranial direct current stimulation (tDCS) for treatment of SSRI resistant OCD. Brain Stimulation. 2015;8(3):655-7.

36. D'Urso G, Brunoni AR, Anastasia A, Micillo M, de Bartolomeis A, Mantovani A. Polarity-dependent effects of transcranial direct current stimulation in obsessive-compulsive disorder. Neurocase. 2016;22(1):60-4.

37. Alizadeh Goradel J, Pouresmali A, Mowlaie M, Sadeghi Movahed F. The effects of Transcranial direct current stimulation on obsession-compulsion, anxiety, and depression of a patient suffering from obsessive-compulsive disorder. Practice in Clinical Psychiatry. 2016;4(2):75-80.

38. Palm U, Leitner B, Kirsch B, Behler N, Kumpf U, Wulf L, Padberg F, Hasan A. Prefrontal tDCS and sertraline in obsessive compulsive disorder: a case report and review of the literature. Neurocase. 2017;23(2):173-7.

39. Hazari N, Narayanaswamy JC, Chhabra H, Bose A, Venkatasubramanian G, Reddy YJ. Response to transcranial direct current stimulation in a case of episodic obsessive compulsive disorder. The journal of ECT. 2016;32(2):144-6.

40. Dinn WM, Aycicegi-Dinn A, Göral F, Karamursel S, Yildirim EA, HaciogluYildirim M, Gansler DA, Doruk D, Fregni F. Treatment-resistant obsessivecompulsive disorder: insights from an open trial of transcranial direct current stimulation (tDCS) to design a RCT. Neurol Psychiatry Brain Res. 2016;22(3-4):146-54.

41. Najafi K, Fakour Y, Zarrabi H, Heidarzadeh A, Khalkhali M, Yeganeh T, Farahi $H$, Rostamkhani M, Najafi T, Shabafroz S. Efficacy of transcranial direct current stimulation in the treatment: resistant patients who suffer from severe obsessive-compulsive disorder. Indian J Psychol Med. 2017;39(5):573-8.

42. Yekta M, Rostami R, Fayyaz E. Transcranial direct current stimulation of dorsolateral prefrontal cortex in patients with obsessive compulsive disorder to improve decision making and reduce obsession symptoms. Practice in Clinical Psychology. 2015;3(3):185-94.

43. Gowda SM, Narayanaswamy JC, Hazari N, Bose A, Chhabra H, Balachander S, Bhaskarapillai B, Shivakumar V, Venkatasubramanian G, Reddy YJ. Efficacy of pre-supplementary motor area transcranial direct current stimulation for treatment resistant obsessive compulsive disorder: a randomized, double blinded, sham controlled trial. Brain stimulation. 2019;12(4):922-9.

44. Bation R, Mondino M, Le Camus F, Saoud M, Brunelin J. Transcranial direct current stimulation in patients with obsessive compulsive disorder: a randomized controlled trial. European Psychiatry. 2019;62:38-44.

\section{Publisher's Note}

Springer Nature remains neutral with regard to jurisdictional claims in published maps and institutional affiliations.
Ready to submit your research? Choose BMC and benefit from:
- fast, convenient online submission
- thorough peer review by experienced researchers in your field
- rapid publication on acceptance
- support for research data, including large and complex data types
- gold Open Access which fosters wider collaboration and increased citations
- maximum visibility for your research: over $100 \mathrm{M}$ website views per year
At BMC, research is always in progress.
Learn more biomedcentral.com/submissions 